\title{
Priority at Discharge Code
}

National Cancer Institute

\section{Source}

National Cancer Institute. Priority at Discharge Code. NCI Thesaurus. Code C153107.

A coded value specifying the degree to which a condition is established to be chiefly responsible for occasioning the admission of the patient. 